\title{
PULLING THE PLUG? INVESTIGATING FIRM-LEVEL DRIVERS OF INNOVATION PROJECT TERMINATION
}

Marek Vaculík ${ }^{1,2}$, Annika Lorenz ${ }^{3,4, *}$, Nadine Roijakkers ${ }^{5}$, Wim Vanhaverbeke ${ }^{2,6,7}$

${ }^{1}$ Moravian University College, tř. Kosmonautů 1288/1, Olomouc 779 00, Czech Republic

${ }^{2}$ Hasselt University, Martelarenlaan 42, 3500 Hasselt, Belgium

${ }^{3}$ Utrecht University, Copernicus Institute for Sustainable Development, Heidelberglaan 2, 3584

CS Utrecht, Netherlands

4 Technische Universität Berlin, Faculty of Economics and Management, Chair of Innovation Economics, Marchstraße 23, 10587 Berlin, Germany

${ }^{5}$ Open University of the Netherlands, Faculty of Management Science and Technology, Valkenburgerweg 177, 6401 DL Heerlen, Netherlands

${ }^{6}$ ESADE Business School, Department of Operations, Innovation and Data Sciences, Avenida Pedralbes 60-62, 08034 Barcelona, Spain

${ }^{7}$ National University of Singapore, Division of Engineering and Technology Management, 9 Engineering Drive 1, Blk EA, \#06-10, Singapore 117575.

*Corresponding author: a.lorenz@uu.nl

January 2018 


\title{
PULLING THE PLUG? INVESTIGATING FIRM-LEVEL DRIVERS OF INNOVATION PROJECT TERMINATION
}

\begin{abstract}
Firms need to innovate and develop dynamic capabilities to create a sustainable competitive advantage. Due to this pressure, firms in high-tech industries invest a high percentage of their revenues in innovation. Despite the vast number of innovation success stories, only one in five innovation projects reach the market. It is important to understand the drivers of project termination as many firms make sizable investments in innovation and these drivers may have a significant impact on their innovation performance. Therefore, earlier recognition of unfeasible projects would avoid continued investment and release resources that could be invested in more profitable projects. This paper investigates firm-level factors influencing the termination of innovation projects based on a sample of 4,385 firms in the Czech Republic and Germany. We find that firm size, R\&D activities, organisational agility, and the level of internationalisation are positively associated with innovation project termination. Surprisingly, marketing innovation is also positively associated with project termination. Our results contribute to an improved understanding of why some firms are better at identifying unsuccessful projects (earlier) than others. Identifying generalizable factors provides complementary insights into project-level factors of project termination that can have a remarkable impact on the profitability and survival of firms.
\end{abstract}

\section{Managerial relevance statement}

Innovation is not always a story of success; instead it is often the story of several small and large learning processes. An understanding of why firms abandon innovation projects and what drives termination will help firms improve current processes to avoid unfeasible future projects. Analysing a project upfront regarding feasibility and other problems can result in lower costs and risks. We show results for manufacturing and service sectors for small and large companies in two countries. Small firms and firms with limited innovation budgets are less likely to terminate projects than larger firms with greater innovation experience. This is because larger firms have more codified innovation processes that result in stringent criteria and stage-gates where projects that fail to achieve certain objectives are strictly terminated. Smaller firms possess fewer resources that can be spent on innovation activities. Hence, every investment in innovation is regarded as valuable and a thorough upfront feasibility-success analysis is indispensable. Firms need to ensure that the goals of marketing innovation and new business development projects are well aligned and that there is no misfit between new product design and customer preferences (which increases the likelihood of prematurely terminating an innovative project). But even if an innovation project is terminated it can be a valuable learning opportunity for managing innovation.

Keywords: innovation project termination; innovation process; dynamic capabilities; organisational agility 


\section{INTRODUCTION}

"Companies that don't innovate die" [1]. Innovation is one of the most cited and prominent drivers determining the performance and survival of a firm (e.g. [2] [3]). Hence, innovation activity is the necessary precondition for achieving long-term competitive advantage [4]. The pressure to innovate for firms in high-tech industries results in significant investments in new product development [5] [6]. Despite the vast number of innovation success stories, Asplund and Sandin [7] and Cozijnsen et al. [8] argue that few ideas ever reach the market [6] or are commercially viable. Indeed there are many obstacles hampering innovation activities (e.g. costs, human capital/knowledge, markets, financial barriers, and regulations) [9] - [11]. The more experienced a firm becomes in dealing with these barriers, the better its chances for future success [12]. Experience also fosters the development of the ability to continue innovation projects with a high chance of success while terminating those that are likely to fail.

The decision to terminate an ongoing innovation project before it achieves its goals is difficult because it is usually considered as accepting failure, which few managers are willing to acknowledge [13]. A manager who can make an early and correct decision to terminate an innovation process can save time, money, and other resources, which can be redirected towards more promising and potentially successful activities. In his study, Leoncini [12] shows 'that an unsuccessful innovative activity might ultimately' (p. 385) lead to positive returns, which is in line with studies emphasising the benefits of a terminated innovation project. In an ever more complex and fast-changing environment, in a world of rapid technological change and marketplace turbulences, the effects of these changes on innovation process management and termination are underexplored. This is despite the fact that termination decisions are one of the most difficult and important decisions faced by managers. Therefore, it is necessary to understand the underlying organisational characteristics influencing the termination of unfeasible innovation processes with poor prospects early on - while continuing more promising projects. Despite a tremendous amount of research over the past 30 years, the literature is far 
from demonstrating a cohesive understanding of the determinants of success and failure in innovation projects [14]. Previous studies focus on different sets of factors and there are significant differences regarding the relevance of single factors in explaining the termination of innovation activities. In sum, due to heterogeneity in samples, industries investigated, and methods used, it is difficult to make valid comparisons between these studies. ${ }^{1}$ The lack of integration among the different insights causes gaps in understanding. Therefore, in this paper we add an additional level - the firm level - to provide a starting point for other researchers to take a multi-level approach for studying the termination of innovation activities.

We complement previous project-level research by studying the factors associated with innovation termination at the firm level - such as organisational agility and marketing innovation. Our research question is: 'What are the firm-level factors determining the termination of innovation endeavours by firms?' This question is important since many firms spend a significant budget on innovation projects that do reach commercialisation. Firstly, these expenditures embody a sizable investment for many firms and may have a significant impact on their current and future financial position, as well as on their ability to compete technologically. Secondly, projects often entail company-wide commitments that translate into large opportunity costs if improperly managed [4]. Thirdly, being able to recognise unfeasible projects early on avoids sunk investments and releases resources that can be invested in more profitable projects.

In this paper, we aim to throw light on the firm-level factors influencing the termination of innovation activity.

We use a sample of 4,385 firm observations to understand their innovation behaviour, and specifically, the firm-level factors associated with innovation termination. We find that firm size, R\&D activity, organisational agility, marketing innovation, and market internationalisation

Samples differ as some studies investigate a specific industry, and others cover several industries. Methods differ, as some studies are qualitative while others are quantitative. The methods applied often determine the factors used for project termination [13]. 
are significantly positively associated with innovation termination. ${ }^{2}$ Our research contributes to the literature studying the success and failure factors of innovation endeavours by firms in general [15], and the literature dealing with innovation project termination in particular [16]. In doing so, we raise researcher and practitioner awareness regarding the underlying firm-level factors driving the termination of innovation endeavours. Based on our research, firms can analyse their innovation project management and spending behaviour. In this paper we argue that the termination of innovation projects (although the projects themselves can be considered as failures) is a laudable management practice and an effective detection of such failures is necessary to avoid waste of time and high costs in continuing projects. Thus, firms can prevent overspending on innovation, which the literature found to be correlated with innovation project termination [6], [17]-[19]. In sum, this paper advocates for termination of a project as a valuable learning opportunity and a proper way of handling less promising innovation projects.

The paper is organised as follows: Section II reviews the theoretical literature on the subject and Section III presents hypotheses for empirical testing; Section IV describes the data, the econometric method used, and the measurement of our main variables; Section V presents the results, and Section VI concludes with a discussion of the main findings and provides some implications for further research.

\section{LITERATURE REVIEW}

We provide below a review of the relevant literature on innovation management focusing on the determinants of success and failure in innovation activities and the barriers to innovation. We then present dynamic capabilities as the framework for analysing innovation process management in firms with regard to the termination of innovation endeavours.

2 We mainly refer to correlations with our analysis since our data is cross-sectional. Nonetheless, we interpret that firms with certain characteristics are more likely to terminate projects. 


\section{A. Success/failure in innovation endeavours}

One important stream within the innovation management literature deals with understanding the critical success factors during the innovation process. 'As innovative activity is inherently uncertain, it often results in termination or even failure.' [12] (p. 376). Several studies on firms explicitly identify specific success [14], [20]-[24] and failure factors [16] driving innovation performance. Van der Panne et al. [14] study factors influencing the viability of a new product and classify them into four different groups: firm-related factors; project-related factors; product-related factors; and market-related factors. They further differentiate firm-related and project-related factors as determinants of technological viability, while product-related and market-related factors are described as determinants of commercial viability. Firm-related factors driving technological success are: firm culture [25] [26]; experience with innovation [27]-[30]; characteristics of the R\&D team such as interdisciplinarity [31]-[34]; and strategy towards innovation [35] [36]. Previous studies are discordant about the influence of organisational structure and R\&D intensity [14] [30] on innovation project success.

Project-related factors affecting successful completion of an innovation project are the complementarity of the project with the firm's resources [27] [37] [38] and management style [8] [39] [40]. Finally, top management support is argued to be an ambivalent factor for innovation project viability.

With respect to the product's commercial viability, two product-related factors (i.e. price [23] and quality [25] [33] [41]) and two market-related factors (i.e. market concentration [33] and market introduction [23] [42]) are acknowledged as success factors. ${ }^{3}$ Previous studies address barriers to innovation (e.g. costs, missing access to human capital/knowledge, markets, organisational inertia, financial barriers, and regulatory obstacles). Particular attention has been paid to financial constraints as these can apparently be major barriers to innovation [43]-[47].

\footnotetext{
External factors affecting the success/failure of an innovation project are less relevant for the purpose of our study. We only possess internal firm information. However, we mention them here for completeness.
} 
The financial capacity of a firm seems to have a significant impact on the early stages of innovative projects (stopping projects prematurely or seriously delaying projects), whereas they do not affect innovative activities already well underway [43]. Additionally, firms collaborating on innovation have been found to abandon or delay their innovation projects due to difficulties in partnerships [20]. In contrast, firms with a certain level of absorptive capacity are less likely to experience failures in their innovative activities [48]. Although the decision to terminate an innovation activity can occur at any point along the pipeline, it frequently happens at the end of the development phase. To grasp the significance of a termination decision, a brief explanation of the innovation process and related barriers may be helpful [6].

Typically, an innovation process describes a pre-defined sequence of phases from idea generation to problem-solving to commercialisation [49] [50]. Each of these phases comprises inherent risk and reviews in terms of stage-gate processes [51]. A project will only be continued if it meets all the deliverables at the phase/stage gate. Iterative feedback further augments project development during these stages. Termination risks associated with the idea generation phase - the phase in which a new product or process concept with the functionality and specification criteria is defined [52] - comprise issues regarding intellectual property held by other entities, internal competition from other more promising ideas, project cost forecasts that exceed budget, and insufficient in-house knowhow to complete the project. In the problemsolving phase, innovation investments are made, $\mathrm{R} \& \mathrm{D}$ is conducted, the close-to-optimal design of the innovation is developed, and critical design components are shared. Therefore, termination of a project in this phase may be due to insufficient in-house technical and production knowledge, insufficient financial or physical resources, insufficient internal support if the prototype does not live up to its expectation or deliver the expected results and/or benefits, a lack of support from top management, lack of commitment from project workers, higher

\footnotetext{
4 Saren (1984) provides a review of different descriptive innovation process models. We conceptualise the stages
} according to Utterback (1971); Utterback (1974) and Tushman (1977). 
development costs than initially budgeted, and issues regarding intellectual property held by other entities. Problems that cause the termination of a marketable product in the commercialisation phase relate to incorrect understanding of customer needs, product defects, lack of an effective marketing effort, higher than expected product launch costs, strong competition, bad timing, a product price that is too high, insufficient marketing efforts, radicalness of the new product (newness to firm and/or to market), and sales force or distribution weaknesses [53].

Within the innovation process literature, research provides a long track record of the drivers of innovation project termination [54] - [58].

In sum, several studies have identified factors to distinguish between successful and unsuccessful innovation projects [54]. Literature shows that the success or failure of an innovation project is determined by a combination of factors rather than by any single factor. Moreover, previous studies present different discriminant factors of success and failure projects, but there is no study containing completely the same set of factors. Hence, comparability across studies is difficult. For example, Tadisina [55] identifies 23 variables grouped into five categories: (1) uncertainty at project initiation; (2) pressure to start project; (3) expected impact; (4) science and technology areas; and (5) intention to protect project outcomes. Balachandra [19] groups the determinants into seven categories, namely: strategic; economic; environmental; technological; operational; behavioural; and organisational. Rubenstein et al. [56] classify the variables into six categories as follows: factors related to impetus for innovation; factors related to project decision; factors related to project structure and process; factors related to organisational structure and process; factors related to outcomes; and other factors [13]. Raelin and Balachandra [6] suggest that strategic parameters of the high-technology research environment (such as high rates of product turnover, high market share, and small size) were found to lead to continuations; whereas infancy stage product life cycle and innovative versus aligned research strategy led to terminations. Holzmann [57] argues that innovation projects 
should be terminated when they are proven technically unfeasible or economically unsound [13]. Furthermore, Balachandra [19] investigates determinants of innovation project termination in an international context and finds a remarkable consistency across the set of 27 factors discriminating between successful and failing R\&D projects in Japan, UK, USA, and Germany.

Despite a vast number of studies detecting various project-level termination factors, the firmlevel determinants of innovation determination remain underexplored. Understanding what drives the termination of innovation endeavours at the firm level may provide complementary insights to the non-comparable, project-level factors that were identified by previous research. We can thus derive some more generalizable and relevant factors driving the termination of innovation endeavours. ${ }^{5}$ Although, firm-level factors are often independent of the projects themselves, they nevertheless exert an indirect influence on the overall firm innovation project management process. By focusing on firm-level innovation termination, this study provides firms with support to fully exploit their innovative potential as they continue to eliminate obstacles to their innovative activity, and hence maximise their innovative efforts.

\section{B. Dynamic capabilities}

Firms in today's ever more complex and fast changing business world need the dynamic capabilities - in contrast to ordinary capabilities - to be able to react quickly and flexibly to internal and external changes. Hence, the dynamic capabilities of a firm represent an essential element of innovation process management. As discussed above, innovation management requires timely and flexible decision-making to address rapidly changing environments such as in the case of innovation termination. In inherently uncertain situations, such as the innovation process, dynamic capabilities represent a new approach to manage deep (unqualifiable) uncertainty. Dynamic capabilities closely relate to the management capability to effectively

\footnotetext{
5 In the context of our study, we understand successful innovation as an activity that is not discontinued at any stage. We interpret the termination of an innovation activity as a deviation from an expected outcome (i.e. successful commercialisation or introduction of a new product/process).
} 
coordinate and redeploy internal and external competences [58]. Coupled with a validated strategy, dynamic capabilities enable an organisation to change in a manner that supports evolutionary fitness and sustainable competitive advantage. A company should not be just focused on control and oversight, but on thinking creatively about new projects and business opportunities and executing them proficiently. Termination of an on-going activity requires agile and fast reactions to unforeseen or unexpected change and has thus been discussed in the context of dynamic capabilities [58]-[60]. Particularly, innovation termination entails a transformational culture and strong leadership that can realign tangible and intangible assets, strategy, structure, and processes.

Moreover, dynamic capabilities are not only beneficial in dealing with innovation termination, they can also be enhanced by the termination of innovation activities. In turn, not developing dynamic capabilities after the discontinuation of innovation activities can also be detrimental for the recovery, profitability, and survival of a firm after experiencing such a situation.

\section{HYPOTHESES}

In this section, we discuss the determinants of innovation project termination and develop testable hypotheses. The most important factors leading to successful innovation outcomes are deemed to be firm size, age, experience with innovation projects, existence of an R\&D department, and interfirm collaboration. Previous research has also identified several barriers to successful innovation such as missing access to know-how on markets or technologies [9], lack of finance [61], organisational inertia [62], or regulation [10]. We complement these previous studies by adding relevant firm-level determinants associated with innovation termination such as internal/external $\mathrm{R} \& \mathrm{D}$, organisational agility, level of internationalisation, and marketing innovation. 


\section{A. Firm size}

In contrast to SMEs, larger firms can employ economies of scale and scope when it comes to innovation projects and thus create transaction cost benefits. Established firms have the financial capacity to generate new product development projects with substantial economic benefits ('valuable patents') [63]-[65]. They often also have established routines to effectively screen the internal and external environment of the firm and analyse whether an on-going project is still viable and promising. Nonetheless, large firms usually face decreasing returns to scale in innovation projects [66]. Larger firms are less efficient than smaller firms due to greater bureaucracy and routinisation. Additionally, reduced managerial commitment to innovation, and a stronger focus on ordinary capabilities and operational routines leads to lower innovative efficiency for firms [67], as well as the risk of inventive opportunities being exhausted over time (translating into a lower rate of commercialisable products per innovation project started) [66], [68], [69]. According to the resource-based view, smaller firms possess fewer resources to invest in new innovation projects [70], [71].

Hence, smaller firms might hold on to innovation projects longer. These firms will only start an innovation project when they are convinced that it might be a success. Larger firms can easily neglect a project that does not perform according to expectations as these firms possess more resources that can be invested in other projects. We would expect larger firms to be more likely to cancel an on-going innovation project than a small firm.

Hypothesis 1: Firm size is positively associated with the likelihood of terminating an innovation project.

\section{B. Internal and external R\&D}

Investing in $R \& D$ is associated with an increase in total innovative output (see e.g., [72]-[74]. Engaging in research activities enables firms to explore, develop new competences, and capabilities. At the same time, firms may also develop new products or processes that have a significant impact on their financial performance. Previous research has differentiated between 
internal and external R\&D (e.g. [73], [75]). In the realm of open innovation, several studies suggest that firms increasingly rely on external sources of knowledge in innovation and thus simultaneously pursue internal and external R\&D [1], [76]. External R\&D can thus be an important source for improving and accelerating internal $R \& D$. In turn, internal $R \& D$ and building absorptive capacity [30] are important for recognising, assimilating, and exploiting relevant external knowledge. With sufficient in-house knowledge, a firm can effectively absorb external spillovers [73], [75]. Although some studies argue that internal and external R\&D are substitutes [77], the open innovation literature clearly suggests complementarity between internal and external R\&D [66], [72], [73], [78]. Hence, combining internal and external R\&D significantly contributes to productivity growth due to 'involvement in multiple technological trajectories, research directions that cannot be developed simultaneously (at sufficient speed), and in-house and external development skills exploiting in-house research activities more effectively' [73]: p. 401. Moreover, Brouwer et al. [79] find that the relationship between internal/external $R \& D$ and innovative output is influenced by factors such as regional knowledge spillovers, demand-pull effects, or differences in technological opportunity. Such factors can explain that R\&D input and innovative output are far less correlated than one would intuitively expect. Thus, a similar line of arguments as above can be made here. Investing in many internal and external innovation projects simultaneously requires more formalisation to monitor the status of the projects. In that line of argument, companies conducting more R\&D will become more formalised, and therefore termination will be decided on more objective criteria. In contrast, firms with few R\&D investments have no formalised system in place, and will continue projects as long as managers believe in them. This typically leads to overcommitment to poorly performing innovation projects [80]. Therefore, investing more resources in R\&D usually increases the risk of innovation project termination. We formulate the following hypothesis: 
Hypothesis 2: Conducting internal and external R\&D is positively associated with the likelihood of terminating an innovation project.

\section{Organisational agility}

Organisational agility is important for the economic sustainability of firms. Building dynamic capabilities through organisational innovation is a "necessary precondition for technological innovation' [81]. Thus, a firm's technology base is necessary - but it is not the only precondition of market success. There is a need for new capabilities and organisational arrangements within companies to fully exploit and manage technological innovation activities.

The ability to renew means that a firm can constantly evolve due to proactive search for and utilisation of new knowledge and innovations to recombine its core competencies and/or make changes in its product market domain [82]. But such a change never comes easy as strong and enduring inertial forces unleashed by ossified competencies are difficult to overcome. The firm's structures, procedures, and relationships continue to reinforce prior patterns of behaviour and thus resist developing new ones. As a result, organisational changes sometimes result in upheavals and dissatisfaction, and possibly even in resignations and dismissals among employees - also known as the 'not-invented-here' syndrome. In sum, organisational agility can take different forms but changes usually occur in strategic direction, structure, processes, or tasks [83]. Becoming more flexible and agile in times of increasing turbulence and complexity is critical in the long-run. Organisational agility requires employees to concentrate on the changes before focusing on any innovation project. Sometimes employees are allocated to a new project, team, or department that requires additional time and adjustment. Due to these organisational changes, the priorities of firms may alter or need to be adapted to current needs and so they thus abandon current innovation projects in the short-run.

Despite a vast amount of literature arguing that organisational agility is beneficial for achieving long-term competitive advantage [58], any change within the organisational arrangements and routines of a firm makes it vulnerable and may have short-term negative effects on the innovation process. 
Hypothesis 3: Organisational agility is positively associated with the likelihood of terminating an innovation project.

\section{Level of internationalisation}

A firm's level of internationalisation refers to the number of markets a firm actively operates in and assuming that cultural and organisational barriers increase with the number of markets a firm has locations in or sells its products to. ${ }^{6}$ Existing literature mainly deals with the effects of the level of internationalisation on firm performance [84], [85], but findings have to some degree been inconsistent and contradictory. Some scholars have pointed out benefits of internationalisation such as efficient tacit knowledge transfer [86], access to diverse ideas from multiple market and cultural perspectives [87], and scale and scope economies [88]. However, other studies suggest lower firm performance due to the uncertainty of various policy environments [89], increased managerial constraints [90], and the liability of foreignness [91]. According to transaction cost theory, complexity due to internationalisation also associates with higher transaction costs created by language and cultural obstacles which can only partly be justified by economies of scale and scope. Operating on an international scale (i.e. number of markets a firm operates in) also signifies the necessity to stay at the technological frontier and with the need to compete with the best innovator. Hence, firms might be more likely to explore different innovation projects simultaneously. Thus, firms might take greater risks to compete on a larger international level. Operating at the technological frontier also increases the risk of having to terminate some of the ongoing innovation projects early on. Moreover, operating on a highly international scale also increases the level of competition against more and stronger innovators. Hence, the more markets a firm serves, the more competition it will face from firms

$6 \quad$ In this paper, we define market complexity by the number of markets a firm operates in - including local/regional markets, national markets, other EU, EFTA or EU candidate countries, and all other countries. Thus, complexity increases with growing internationalisation. 
with strong skills in research and innovation. To thrive in a highly competitive international context, a firm must be at the forefront of technology as well as possess dynamic capabilities. As a result, the more a firm operates internationally, the stronger its (dynamic) learning capabilities and the more comfortable it should be with abandoning projects that do not seem to be working. Additionally, resources are limited and need to be balanced between investing in daily operating routines or in promising future activities at an international level. Market internationalisation increases complexity for firms but also provides the cash flow required to engage in costly and risky innovation at an efficient scale [92], [93]. However, such risk heavily depends on the industry and technology a firm operates in [94]. Therefore, the more complex the market, the more likely that a firm will interrupt an on-going innovation project because current and daily processes have greater priority than future innovation projects.

Hypothesis 4: Market internationalisation is positively associated with the likelihood of terminating an innovation project.

\section{E. Marketing innovation}

There are few references about marketing innovation in connection with product or process innovation. Scholars often examine the relationships between market orientation (which focuses on market intelligence gathering and dissemination within the organisation and responsiveness to such information [95]) and business performance [96], [97]. The links between market orientation and innovativeness have also been explored by researchers [98]. In our study, we are dealing with practical marketing activities and their innovations. Therefore, we are interested in exploring the relationships between marketing innovations (such as new or changing strategies for product promotion, pricing, and sales channels) and their impact on product and/or process innovation.

Empirical research has shown that the innovation-marketing fit (meaning how companies exploit their marketing capabilities) has a positive impact on the market success of newly launched products [99]. 
Therefore, marketing capabilities should be positively associated with new product development as companies can harvest information from the market and predict customer preferences. As Vorhies et al. [100] show marketing capabilities also positively mediate the product-market strategy and the derived business unit performance relationship. We perceive marketing capabilities here as an 'executive' arm of market orientation because firms need to have the right capabilities to exploit the potential presented in market orientation activities. The better the market capabilities of a firm, the lower the risk of new product development termination. Therefore, we hypothesise:

Hypothesis 5: Marketing innovation is negatively associated with the likelihood of terminating an innovation project.

\section{METHOD}

\section{A. Data}

Community Innovation Surveys (CIS) are conducted in all European Union (EU) member states (sometimes even at a regional level) and are based on the Oslo Manual recommendations [101]-[103]. Innovation surveys exist under different acronyms in many other OECD countries and also in emerging, transition, and developing countries. By and large the surveys have the same structure and the same questions regarding innovation, but there are some differences between countries - even within the CIS - regarding content, formulation, and the ordering of the questions [104]. As a result, CIS data is frequently used (but mainly includes information from one survey in each country) and CIS data is therefore cross-sectional in nature. As discussed above, CIS data has been extensively exploited in numerous ways and researchers now recommend using CIS data to combine different countries or in longitudinal studies [104]. Although this data enables a comparison of national systems of innovation [105] only a few studies have started to incorporate more than one country in their analyses. A few notable studies include contributions by Harrison et al. [106], Czarnitzki and Lopes Bento [107], Horbach et al. [108], Freitas et al. [109] and Therrien and Mohnen [110]. 
Additionally, Leoncini [12] performs a set of empirical estimates on the effect of innovation failure based on a large dataset of innovative firms from 16 countries drawn from the 2008 Community Innovation Survey.

\section{B. Sample}

For our study, we use the German and Czech Community Innovation Survey 2010 (CIS 2010) which includes the core Eurostat CIS and additional topics for firms in Germany. The study is conducted every year and contains a random sample that is stratified by region, size, and sector. ${ }^{7}$ The methodology of the CIS is based on a revised version of the Oslo Manual 2005 [104] which distinguishes four types of innovation: product; process; marketing; and organisational. Product and process innovations are related with technical innovations. Marketing and organisational innovations are recognised as new forms and belong to the group of non-technical innovations. We use CIS data because it includes information on innovation performance and project termination. Here a multitude of innovation termination indicators can be considered to search for the most parsimonious model that fits the data. These indicators range from hampering factors to innovation activities, external sourcing, research collaboration and, least analysed, organisational changes.

Data for CIS 2010 was gathered in 2011 by means of a voluntary postal survey for the period 2008-2010. The target population included all firms with ten or more employees. In total, 5,151 responses were received in the Czech Republic and 6,851 in Germany. We merge both our datasets to total 12,002 observations.

Due to our research design, we restricted the sample to firms that are active in technical innovation (either having introduced product or process innovation) as only those firms actively involved in innovation can experience the termination of their innovation process. The resulting

7 The Oslo Manual opted for the subject approach: that is, data is collected at the firm level - including all innovation outputs and activities. This implies that we do not have data about specific innovation projects [104]. 
dataset has 4,385 observations and is suitable for cross-sectional analyses regarding our dependent and independent variables.

\section{Dependent variable}

We use innovation termination (INTER) as the dependent variable in this study. Specifically, we construct innovation termination using a binary variable measuring whether the firm had an innovation activity between $2008-2010$ that did not result in a product or process innovation because the activity was abandoned or suspended before completion.

\section{Independent variables}

\section{a) Firm size}

Larger companies have more resources, can start more innovation projects, and also have more opportunities to invest in new product development. In our models, we use the natural log of employees in 2008 for the variable Ln-SIZE.

\section{b) Research activities}

The extent of R\&D activities is shown as a very important measure of the innovativeness of individual companies. The values of the variable RESEARCH range from 0 to 2 depending on whether the firm was engaged in in-house $R \& D$ activities and/or external $R \& D$ activities (performed by other companies, or by public or private research organisations and purchased by the firm) during 2008-2010.

c) Organisational agility

The CIS 2010 contains three distinctive binary variables for organisational agility. ORGBUP measures the presence or non-presence of new business practices for organising processes (i.e. lean, quality, and supply chain management) during the period 2008-2010. ORGWKP indicates new methods of organising work responsibilities and decision making (i.e. team work and decentralisation) during the same time period. The ORGEXR variable describes new methods of organising external relations with other firms and institutions. 
In our models, we use the variable ORGIN which is a construct of the three abovementioned variables. We merged them so that origin values range from 0 to 3 depending on whether the firm introduced any of the three distinctive variables presented above.

\section{d) Level of internationalisation}

The values of the variable MARKET range from 0 to 4 depending on which geographical markets the firm sold goods and/or services in during 2008-2010. Thus, the more markets a firm operates in, the higher the level of its internationalisation. There are four possibilities: local/regional market; national market; other EU, EFTA or EU candidate countries; and all other countries.

\section{e) Marketing activities}

The values of the variable MARKETING range from 0 to 4 depending on the introduction of: a) significant changes to the aesthetic design or packaging of a good or service; and/or b) new media or techniques for product promotion; and/or c) new methods for product placement or sales channels, and/or; d) new methods of pricing goods or services during 2008-2010 or 0 otherwise.

\section{Control variables}

a) Industry dummy variables

To check for the industry influence for each company we used the Eurostat indicators on high-tech industry and knowledge-intensive services [111]. We created six groups of industries: low-technology industries; medium low-technology industries; medium high-technology industries; high-technology industries; low knowledge-intensive services; and knowledgeintensive services.

\section{f) Group membership}

Membership in an international group of companies is also assigned importance as these companies have better access to resources and direct information from the market. They also 
have a better capacity to develop new products. In our case, we created a dummy variable. If the company belongs to an international group, the variable value of GROUP is 1 and 0 vice versa.

\section{g) Country dummy variable}

We control for the geographical association with either Germany or the Czech Republic. We created a dummy variable CZECH. If the company is based in the Czech Republic, the variable value is 1 and 0 for companies based in Germany.

\section{RESULTS}

Table 1 shows the mean score, standard deviation, minimum and maximum scores, and number of observations of particular variables. We have also included Cronbach's alpha for our independent variables as these are constructs - with satisfactory scores. The statistics show that $20 \%$ of the firms in our sample terminated an innovation between 2008-2010. The majority of respondents (58\%) are based in Germany compared with Czech Republic (42\%). We further observe that a relatively large number of firms are part of an international group (43\%). Furthermore, the results indicate that about one-third (33\%) of the firms in our sample belong to service industries (25\% knowledge-intensive and $8 \%$ low-intensive knowledge services) compared to $67 \%$ firms belonging to manufacturing industries. Most of the manufacturing firms are part of medium-tech industries (20\%) whereas only $9 \%$ of respondents are active in hightech sectors. For correlations between the variables used in this study see Table 2 . None of the reported correlations are high.

\section{Insert TABLES 1 and 2 about here}

We use logistic regressions in our analysis as our dependent variable (innovation termination 'INTER') is binary. We ran several models in a step-wise manner starting only with control variables and gradually including several independent variables one by one. To check for multicollinearity we conducted a post estimation variance-inflation factor test that excluded collinearity among the independent variables (Table 3). 
The results of our models are shown in Table 4.

\section{Insert TABLES 3 and 4 about here}

Model 1 consists only of control variables followed by models $2-6$ (each with one independent variable). Model 7 is the full model that includes all the variables. The results confirm hypotheses $1,2,3$, and 4 and indicate a significant positive influence for company size, organisational agility, and level of internationalisation on innovation termination. The influence of the variable 'research activities' supports the view that the more the firm is involved in research activities, the higher the probability of innovation project termination. The level of internationalisation also positively associates with the likelihood of terminating an innovation activity.

Surprisingly, there is no support for hypothesis 5 . We find the opposite to be true; marketing innovation is significantly and positively associated with innovation termination.

There are also some interesting results regarding the control variables. Group membership is a statistically significant predictor of innovation termination in all the models. However, there is no statistically significant difference between firms based in the Czech Republic or Germany regarding their propensity to terminate innovation. Finally, the full model (model 7), shows that only low tech firms are significantly less prone to terminate innovation activities compared to high tech firms.

\section{Robustness checks}

We conducted a set of robustness checks to mitigate potential endogeneity and selection bias problems. ${ }^{8}$ Firstly, we divide our dataset into two sub-samples - respondents based in the Czech Republic and in Germany - to check whether there are any significant differences between these countries. We use the same models for the whole sample. Starting with marketing innovation there is no significant influence on innovation termination in the German sub-sample (with the

\footnotetext{
${ }^{8}$ The full results are available upon request.
} 
coefficient -0.0391$)$, but that it is a very strong predictor in the Czech data $\left(0.168^{* * *}\right)$. On the other hand, organisational agility $\left(0.173^{* * *}\right)$ and the level of internationalisation $\left(0.215^{* * *}\right)$ significantly influence the probability of discontinuing innovation activity in the German subsample - but these variables have no significant impact in the Czech sub-sample $(0.0531$ for organisational agility and 0.065 for the level of internalisation). The only predictor having the same significant influence on the dependent variable is internal and external $R \& D\left(0.515^{* * *}\right.$ for Czech and $0.222^{* * *}$ for the German sub-sample). The analysis shows that the results in the combined sample are indeed driven either by Czech or German respondents.

Secondly, we test the robustness of our results regarding the nature of R\&D activity. We differentiate between internal and external $R \& D$ activities. Differences are possible as, for example, external $R \& D$ (that is $R \& D$ performed by other enterprises, or by public or private research organisations, and purchased by the focal firm) may be more prone to discontinuation due to the not-invented-here syndrome. Firms may also lose control over the process and outcomes of research activity performed outside their boundaries. Nevertheless, the results remain stable: both internal and external $R \& D$ have the same significant effect $(0.709 * * *$ respectively $0.340^{* * *}$ ), and the coefficients of other variables are almost identical, so we can argue that there is no added value to distinguish between the two types of R\&D activity in our models.

Thirdly, we checked the robustness of our results - including an additional control for innovation cooperation with other enterprises or non-commercial institutions (excluding pure contracting with no active cooperation). Controlling for cooperation on innovation activities is important since it indicates that a firm is opening its boundaries and reaching out to the vast pool of external knowledge, talents, and products that may have a significant impact (both negative and positive) on its ability to innovate - depending on the right sequence of implementation steps and the firm's attention span. Again, innovation cooperation has no significant effect on 
our dependent variable (coefficient 0.00751) while other values almost remain the same (meaning that our results are not confounded by unobserved effects of innovation cooperation).

Finally, we control for the degree of newness of the product and/or process innovation introduced by the firm during 2008-2010. We possess information about whether an innovative product/process is either new-to-the-market or new-to-the-firm. Firms involved in radical innovation activities (meaning introducing products/processes that are completely new to the market) may be more prone to terminate innovation activities (as these are riskier) than incremental innovation activities (which are more closely aligned with market needs). Nonetheless, this is not the case in our dataset as firms introducing radically new innovation activities are not significantly more prone to terminate projects (coefficient 0.0947 ) than firms introducing only incremental innovations.

\section{DISCUSSION AND CONCLUSION}

This paper examines the factors associated with innovation termination. We distinguish among five factors assumed to play a role in either decreasing (marketing innovation) or increasing (firm size, research activities, organisational agility, level of internationalisation) the probability of innovation termination. In exploring these issues, the paper provides empirical evidence of the firm-level factors influencing innovation termination.

Our main findings contribute to the innovation process management literature in several ways. Firstly, we offer empirical evidence on the relationship between various firm-level factors and the propensity to abandon an innovative activity. Secondly, we are not constrained by any specific industry, and show results for manufacturing and service sectors.

We find that larger firms tend to terminate innovation activities more frequently than their smaller counterparts. Large firms have the advantage that they can rely on formalised evaluation methods for innovation projects, which reduces the chance of an escalation of commitment to projects with poor prospects [112]. Small firms are more selective and only start innovation 
endeavours when there is a good chance that they will become a commercial success. Secondly, firms that are more systematically involved in (internal and external) $R \& D$ activities have a higher propensity to abandon innovation projects. Companies conducting R\&D systematically are more formalised, and therefore the termination of projects is decided on objective criteria. Thirdly, firms that develop new business practices (e.g. increasing agility, quality and supply chain management) and new methods of organising work responsibilities, decision making, and organising relationships with other firms and institutions, also are inclined to terminate more non-promising innovation activities than their counterparts who are not developing such organisational agility. We argue that large companies executing various research activities simultaneously are more prone to abandoning innovation projects than their smaller counterparts with more limited $R \& D$ activities. That does not necessarily mean that larger firms are less innovative. Rather it indicates that larger companies with greater R\&D budgets have a more formalised and objective screening process leading to a higher attrition rate during the selection process. Due to more routinised innovation management [113], these large and resource-intense companies also possess more effective screening mechanisms to detect potentially successful from unsuccessful innovations [114]. These formal control mechanisms include the project management (PM) and stage-and-gate-type systems (SGS) that are needed to create a structure for managing innovation and coordinating between different functional groups within a firm [114], [115]. These controls provide employees engaged in innovation endeavours with an overview of the procedure and sequence for their work, reducing ambiguity about required activities, timelines, and goals [116]. Hence, formalised controls reduce uncertainty and error by terminating unfeasible innovative activities early on. These controls can save considerable money and hence, increase overall performance. Smaller and resource-constrained firms are forced to make tough decisions about a handful of 'safe bets' leading to a lower rate of project terminations. Thus, they hold on to certain innovative activities longer and probably even commercialise innovations that should not have reached market in the first place. Firms that are 
agile and flexible are more likely to terminate innovation projects because they constantly recombine existing resources and evolve in new directions. Such changes in direction open different opportunities and create input for repeatable, new innovation endeavours - but also lead to a higher attrition rate where only few 'winners' successfully emerge from the funnel.

Fourthly, we find that firms that internationalise have to compete in different markets with strong competitors - but they also leverage innovations across various markets and so earn a greater return on innovative products. Firms that operate on a highly international level are also more likely to compete on the frontier of technology and hence they may take more risks across different markets - and this may lead to more innovation activity being terminated. Moreover, international companies are likely to develop objective procedures regulating how to terminate innovative endeavours, thus reducing the risk of commitment escalation by individual managers.

Finally, we find no evidence for our hypothesis that marketing innovation would lead to a reduction in terminating innovation projects. We argued that stronger marketing capabilities would lead to lower risks for innovation termination. The opposite seems true. We explain this surprising result by the fact that firms developing strong marketing capabilities (such as new product promotion techniques, product positioning methods and pricing methods) have additional tools to reject unpromising projects. These additional tools are in addition to the usual tools for objectively estimating the technology performance of a project. These additional tools release more market information and the enhanced screening of the market potential of a new innovation leads to a more formalised scrutiny of progress - and hence earlier termination when market expectations are unmet. Innovation process research has usually treated the innovation process as a linear sequence of functional activities [117], [118]. A key problem with innovation is that firms need to make sense of a complex, uncertain, and highly risky environment.

Our results have some relevant managerial implications. Our research contributes to a better understanding of barriers to innovation by improving the ability of firms to recognise sources of failure. Hence, they can continue to eliminate firm-level obstacles to innovative activity, and so 
maximise innovative efforts. All the factors examined in this paper positively contribute to innovation termination: increasing the incidence of project termination can be perceived as harmful to overall innovation performance by firms, but terminating less promising projects helps firms to fully exploit their innovation potential in the long-run. Establishing effective and flexible screening mechanisms to detect successful from potentially unsuccessful innovations can save a considerable amount of money and hence, increase overall performance.

As organisational agility is consistently associated with terminating an innovative endeavour, independently of industry sector and innovation quality, there is a need to find the right organisational setting for innovation. Firms must continuously search for changes in procedures and business practices to respond to market demands and develop commercially viable products. Our results contribute to the debate about whether innovation can be managed despite its enormously complexity and uncertainty. Our results show that in addition to problems in applying and adapting basic knowledge to new products and processes, we find additional firmlevel factors contributing to that uncertainty. Yet despite these potential barriers to success, it is possible to identify some underlying patterns of success. In this paper we argue that the termination of innovation projects is a laudable management practice and an effective detection of such failures is necessary to avoid waste of time and high costs in continuing projects. Even if an innovation fails, responding to and managing such failure appears to be a valuable learning opportunity - and this improves the chances of successful future innovation. Thus learning from innovation termination creates the foundation for efficiently and successfully managing innovation. Particularly in cases of low $(R \& D)$ productivity and high late-stage attrition rates, so called 'quick-kill' strategies promote fast learning curves as they seek to bring forward decisions to terminate projects to an earlier point in the process [17]. Hence, based on our findings, we analyse factors within firms that make a successful innovation more likely despite high levels of uncertainty. As the innovation process involves dealing with uncertainty it should provide enough flexibility to help monitor and adapt projects over time - but also enough rigour to 
justify termination of projects when the unknown becomes known. Knowledge is gathered at an increasing cost - but uncertainty decreases and so becomes calculated risk.

\section{Limitations and further research}

While our study provides important contributions and shows that firm size, research activities, level of internationalisation, as well as organisational agility, can be important factors for innovation project termination, some questions remain unanswered - providing exciting opportunities for further research. A problem that arises is the capacity of managers to maintain and control different innovation projects at the same time [119]. Hence, it might be more difficult to handle projects of different types (e.g., marketing innovation and product innovation projects) than projects of one type (e.g., process innovation). Therefore, it would be interesting to contribute to the innovation process management literature by examining whether the (coordination and transaction cost) effort increases when a firm engages in interrelated innovation projects compared to unrelated projects. Thus, future research could investigate firm portfolios regarding different types of innovation projects. Furthermore, our findings do not account for the frequency, nor the number of a firm's innovation termination experiences. Nonetheless, this indicates a potential for organisational learning triggered by the negative experience and leaves room for firms to design an organisational culture that strongly support employees learning from the termination of unpromising projects, rather than considering each project termination as a failure. This opens interesting avenues for further research using organisational learning theory (e.g., [120]-[122]) to analyse the development of innovation project management capabilities within firms to reduce the likelihood of further unwanted innovation project terminations. Therefore, it would be interesting and highly rewarding for theory building on the creation of innovation project management capability by firms to investigate the drivers and reasons for innovation project termination. In light of the organisational learning and dynamic capabilities literature [58]-[60], further research should aim to learn from terminations (and their intrinsically dynamic nature) and whether this increases or 
decreases the number of future terminations and hence has a positive impact on overall innovation performance. Moreover, we encourage future research to incorporate control mechanisms such as PM or SGS in their models - and include the degree of innovativeness as a moderating factor and show to what extent control mechanisms influence innovation termination.

Furthermore, we encourage future research to take a multi-level perspective by studying combined project and firm-level factors of innovation project termination to gain a more integral understanding. Finally, we suggest extending our findings by specifically differentiating between innovation projects building on core/non-core technologies and the impact on innovation project termination. Innovation projects building on core-technologies may be less prone to termination than projects that are more radical and/or based on non-core technologies.

The empirical evidence presented in this article should be considered carefully as the data collected in innovation surveys is qualitative, subjective, censored, and cross-sectional [104]. In this vein, we can neither account for the number of projects the firms in our sample are simultaneously working on, nor the absolute number of projects terminated. We also do not know at which stage of the process the projects were terminated. We cannot link the effective termination of innovation projects to a firm's innovation performance as we do not have the data. There should also be a time lag between independent and dependent variables to induce causality. These limitations represent a potential for interesting future research questions. Another limitation of this study lies in the fact that the survey is subjective and based on assertions by individual managers on their company's termination behaviour. Although the reliability and validity of the survey has been established, some questions may remain slightly subjective and rely on the perception of the respondent and his/her involvement in innovation activities. These limitations offer a wide and valuable spectrum of potential future research questions and increasingly relevant contributions in the realm of innovation process management and new product development. 
TABLES

Table 1: Descriptive statistics

\begin{tabular}{|c|c|c|c|c|c|c|}
\hline VARIABLES & $\begin{array}{l}(1) \\
\mathrm{N} \\
\end{array}$ & $\begin{array}{c}(2) \\
\text { Mean } \\
\end{array}$ & $\begin{array}{l}(3) \\
\text { S.D. }\end{array}$ & $\begin{array}{l}(4) \\
\min \end{array}$ & $\begin{array}{c}(5) \\
\max \\
\end{array}$ & $\begin{array}{c}(6) \\
\text { Cronbach } \\
\end{array}$ \\
\hline INTER & 4385 & 0.204 & 0.403 & 0 & 1 & \\
\hline MARKETING & 4385 & 1.253 & 1.289 & 0 & 4 & 0.65 \\
\hline ORGIN & 4385 & 1.284 & 1.131 & 0 & 3 & 0.66 \\
\hline MARKET & 4385 & 2.566 & 1.109 & 0 & 4 & 0.50 \\
\hline RESEARCH & 4385 & 0.970 & 0.784 & 0 & 2 & 0.51 \\
\hline Ln_SIZE & 4385 & 4.533 & 1.561 & 2.30 & 12.95 & \\
\hline GROUP & 4385 & 0.460 & 0.498 & 0 & 1 & \\
\hline $\mathrm{CZECH}$ & 4385 & 0.464 & 0.498 & 0 & 1 & \\
\hline HIGH_TECH & 4385 & 0.088 & 0.284 & 0 & 1 & \\
\hline MEDIUM_HIGH_TECH & 4385 & 0.209 & 0.406 & 0 & 1 & \\
\hline MEDIUM_LOW_TECH & 4385 & 0.159 & 0.366 & 0 & 1 & \\
\hline LOW_TECH & 4385 & 0.187 & 0.390 & 0 & 1 & \\
\hline OTHER & 4385 & 0.041 & 0.198 & 0 & 1 & \\
\hline KNOW_SERV & 4385 & 0.228 & 0.420 & 0 & 1 & \\
\hline LOW_KNOW_SERV & 4385 & 0.084 & 0.278 & 0 & 1 & \\
\hline
\end{tabular}


Table 2: Correlation matrix

\begin{tabular}{|c|c|c|c|c|c|c|c|c|c|c|c|c|c|c|c|}
\hline & (1) & (2) & (3) & (4) & (5) & (6) & (7) & (8) & (9) & (10) & (11) & (12) & (13) & (14) & (15) \\
\hline INTER (1) & 1.00 & & & & & & & & & & & & & & \\
\hline MARKETING (2) & 0.09 & 1.00 & & & & & & & & & & & & & \\
\hline ORGIN (3) & 0.13 & 0.38 & 1.00 & & & & & & & & & & & & \\
\hline MARKET (4) & 0.12 & 0.08 & 0.09 & 1.00 & & & & & & & & & & & \\
\hline RESEARCH (5) & 0.18 & 0.16 & 0.23 & 0.30 & 1.00 & & & & & & & & & & \\
\hline Ln-SIZE (6) & 0.16 & 0.10 & 0.23 & 0.24 & 0.24 & 1.00 & & & & & & & & & \\
\hline GROUP (7) & 0.12 & 0.05 & 0.19 & 0.14 & 0.16 & 0.49 & 1.00 & & & & & & & & \\
\hline CZECH (8) & 0.01 & -0.08 & 0.05 & -0.01 & 0.06 & 0.06 & 0.10 & 1.00 & & & & & & & \\
\hline HIGH_TECH (9) & 0.04 & 0.01 & 0.03 & 0.13 & 0.14 & -0.03 & -0.01 & -0.10 & 1.00 & & & & & & \\
\hline MEDIUM_HIGH_TECH (10) & 0.04 & -0.05 & 0.01 & 0.21 & 0.17 & 0.17 & 0.13 & 0.01 & -0.16 & 1.00 & & & & & \\
\hline MEDIUM_LOW_TECH (11) & 0.01 & -0.05 & -0.02 & 0.11 & 0.04 & 0.09 & 0.03 & 0.06 & -0.13 & -0.22 & 1.00 & & & & \\
\hline LOW_TECH (12) & -0.01 & 0.06 & -0.08 & -0.01 & -0.12 & -0.06 & -0.10 & 0.03 & -0.15 & -0.24 & -0.21 & 1.00 & & & \\
\hline OTHER (13) & -0.01 & -0.02 & 0.00 & -0.17 & -0.10 & 0.01 & 0.01 & 0.07 & -0.06 & -0.10 & -0.09 & -0.10 & 1.00 & & \\
\hline KNOW_SERV (14) & -0.01 & 0.04 & 0.05 & -0.22 & -0.03 & -0.17 & -0.05 & -0.07 & -0.16 & -0.27 & -0.23 & -0.26 & -0.11 & 1.00 & \\
\hline LOW_KNOW_SERV (15) & -0.05 & 0.01 & 0.00 & -0.11 & -0.16 & 0.00 & 0.00 & 0.00 & -0.09 & -0.15 & -0.13 & -0.14 & -0.06 & -0.16 & 1.00 \\
\hline
\end{tabular}


Table 3: Post estimation VIF test

$\begin{array}{llc}\text { Variable } & \text { VIF } & 1 / \text { VIF } \\ \text { Ln_SIZE } & 11.58 & 0.086344 \\ \text { MARKET } & 6.59 & 0.151808 \\ \text { RESEARCH } & 3.19 & 0.313834 \\ \text { ORGIN } & 2.97 & 0.337108 \\ \text { MEDIUM_HIGH_TECH } & 2.64 & 0.379189 \\ \text { GROUP } & 2.48 & 0.403875 \\ \text { MARKETING } & 2.39 & 0.418083 \\ \text { LOW_TECH } & 2.23 & 0.448053 \\ \text { MEDIUM_LOW_TECH } & 2.20 & 0.454270 \\ \text { KNOW_SERV } & 2.12 & 0.472126 \\ \text { CZECH } & 1.99 & 0.501893 \\ \text { LOW_KNOW_SERV } & 1.54 & 0.647906 \\ \text { OTHER } & 1.28 & 0.778678 \\ \text { Mean } & 3.32 & \end{array}$


Table 4: Logistic regressions on innovation project termination

\begin{tabular}{|c|c|c|c|c|c|c|c|}
\hline VARIABLES & $\begin{array}{c}(1) \\
\text { Model } 1 \\
\end{array}$ & $\begin{array}{c}(2) \\
\text { Model } 2 \\
\end{array}$ & $\begin{array}{c}(3) \\
\text { Model } 3 \\
\end{array}$ & $\begin{array}{c}(4) \\
\text { Model } 4 \\
\end{array}$ & $\begin{array}{c}(5) \\
\text { Model } 5 \\
\end{array}$ & $\begin{array}{c}\text { (6) } \\
\text { Model } 6 \\
\end{array}$ & $\begin{array}{c}(7) \\
\text { Model } 7 \\
\end{array}$ \\
\hline Ln_SIZE & & $\begin{array}{l}0.217 * * * \\
(0.0279)\end{array}$ & & & & & $\begin{array}{l}0.138 * * * \\
(0.0292)\end{array}$ \\
\hline MARKETING & & & $\begin{array}{l}0.177 * * * \\
(0.0289)\end{array}$ & & & & $\begin{array}{l}0.0723 * * \\
(0.0326)\end{array}$ \\
\hline ORGIN & & & & $\begin{array}{l}0.250 * * * \\
(0.0344)\end{array}$ & & & $\begin{array}{l}0.117 * * * \\
(0.0390)\end{array}$ \\
\hline MARKET & & & & & $\begin{array}{l}0.240 * * * \\
(0.0382)\end{array}$ & & $\begin{array}{l}0.131 * * * \\
(0.0405)\end{array}$ \\
\hline RESEARCH & & & & & & $\begin{array}{l}0.541 * * * \\
(0.0530)\end{array}$ & $\begin{array}{l}0.403 * * * \\
(0.0565)\end{array}$ \\
\hline $\mathrm{CZECH}$ & $\begin{array}{l}-0.00490 \\
(0.0772)\end{array}$ & $\begin{array}{l}-0.000238 \\
(0.0785)\end{array}$ & $\begin{array}{l}0.0402 \\
(0.0779)\end{array}$ & $\begin{array}{l}-0.0357 \\
(0.0779)\end{array}$ & $\begin{array}{l}0.0145 \\
(0.0777)\end{array}$ & $\begin{array}{l}-0.0515 \\
(0.0783)\end{array}$ & $\begin{array}{l}-0.0254 \\
(0.0807)\end{array}$ \\
\hline GROUP & $0.634 * * *$ & $0.308^{* * *}$ & $0.601 * * *$ & $0.530 * * *$ & $0.576 * * *$ & $0.529 * * *$ & $0.257 * * *$ \\
\hline MEDIUM_HIGH_TECH & $\begin{array}{l}(0.0777) \\
-0.181 \\
(0.142)\end{array}$ & $\begin{array}{l}(0.0894) \\
-0.326 * * \\
(0.145)\end{array}$ & $\begin{array}{l}(0.0781) \\
-0.155 \\
(0.143)\end{array}$ & $\begin{array}{l}(0.0793) \\
-0.139 \\
(0.143)\end{array}$ & $\begin{array}{l}(0.0785) \\
-0.180 \\
(0.142)\end{array}$ & $\begin{array}{l}(0.0791) \\
-0.111 \\
(0.144)\end{array}$ & $\begin{array}{l}(0.0909) \\
-0.205 \\
(0.147)\end{array}$ \\
\hline MEDIUM_LOW_TECH & $\begin{array}{l}-0.317 * * \\
(0.151)\end{array}$ & $\begin{array}{l}-0.426 * * * \\
(0.154)\end{array}$ & $\begin{array}{l}-0.291^{*} \\
(0.152)\end{array}$ & $\begin{array}{l}-0.251 \\
(0.153)\end{array}$ & $\begin{array}{l}-0.287^{*} \\
(0.152)\end{array}$ & $\begin{array}{l}-0.165 \\
(0.154)\end{array}$ & $\begin{array}{l}-0.225 \\
(0.157)\end{array}$ \\
\hline LOW_TECH & $\begin{array}{l}-0.321 * * \\
(0.148)\end{array}$ & $\begin{array}{l}-0.367 * * \\
(0.150)\end{array}$ & $\begin{array}{l}-0.367 * * \\
(0.149)\end{array}$ & $\begin{array}{l}-0.243 \\
(0.150)\end{array}$ & $\begin{array}{l}-0.227 \\
(0.149)\end{array}$ & $\begin{array}{l}-0.0368 \\
(0.152)\end{array}$ & $\begin{array}{l}-0.0815 \\
(0.157)\end{array}$ \\
\hline OTHER & $\begin{array}{l}-0.449 * * \\
(0.226)\end{array}$ & $\begin{array}{l}-0.612 * * * \\
(0.235)\end{array}$ & $\begin{array}{l}-0.447 * * \\
(0.227)\end{array}$ & $\begin{array}{l}-0.416^{*} \\
(0.228)\end{array}$ & $\begin{array}{l}-0.124 \\
(0.233)\end{array}$ & $\begin{array}{l}-0.0392 \\
(0.233)\end{array}$ & $\begin{array}{l}-0.0870 \\
(0.248)\end{array}$ \\
\hline KNOW_SERV & $\begin{array}{l}-0.396 * * * \\
(0.143)\end{array}$ & $\begin{array}{l}-0.351^{* *} \\
(0.145)\end{array}$ & $\begin{array}{l}-0.420 * * * * \\
(0.144)\end{array}$ & $\begin{array}{l}-0.397 * * * * \\
(0.144)\end{array}$ & $\begin{array}{l}-0.187 \\
(0.147)\end{array}$ & $\begin{array}{l}-0.174 \\
(0.146)\end{array}$ & $\begin{array}{l}-0.0958 \\
(0.152)\end{array}$ \\
\hline LOW_KNOW_SERV & $\begin{array}{l}-0.837 * * * \\
(0.194)\end{array}$ & $\begin{array}{l}-0.941 * * * \\
(0.199)\end{array}$ & $\begin{array}{l}-0.862^{* * * *} \\
(0.195)\end{array}$ & $\begin{array}{l}-0.803^{* * * *} \\
(0.195)\end{array}$ & $\begin{array}{l}-0.643^{* * *} \\
(0.197)\end{array}$ & $\begin{array}{l}-0.438^{* *} \\
(0.200)\end{array}$ & $\begin{array}{l}-0.505 * * \\
(0.207)\end{array}$ \\
\hline Constant & $\begin{array}{l}-1.365 * * * \\
(0.125)\end{array}$ & $\begin{array}{l}-2.162 * * * \\
(0.166)\end{array}$ & $\begin{array}{l}-1.602 \text { *** } \\
(0.132)\end{array}$ & $\begin{array}{l}-1.684 * * * \\
(0.135)\end{array}$ & $\begin{array}{l}-2.083^{* * * *} \\
(0.171)\end{array}$ & $\begin{array}{l}-2.062 * * * \\
(0.146)\end{array}$ & $\begin{array}{l}-3.018 \text { *** } \\
(0.203)\end{array}$ \\
\hline Observations & 4,385 & 4,385 & 4,385 & 4,385 & 4,385 & 4,385 & 4,385 \\
\hline 11 & -2169 & -2099 & -2150 & -2142 & -2148 & -2115 & -2041 \\
\hline chi2 & 97.89 & 158.2 & 134.9 & 151.3 & 138.3 & 205.8 & 275.3 \\
\hline r2_p & 0.0221 & 0.0363 & 0.0304 & 0.0341 & 0.0312 & 0.0464 & 0.0632 \\
\hline $\mathrm{p}$ & 0 & 0 & 0 & 0 & 0 & 0 & 0 \\
\hline
\end{tabular}

Note: 'High-tech' is the default category. Standard errors in parentheses, ${ }^{* *} \mathrm{p}<0.01,{ }^{*} \mathrm{p}<0.05,{ }^{*} \mathrm{p}<0.10$. 


\section{REFERENCES}

[1] H. W. Chesbrough, Open Innovation: The New Imperative for Creating and Profiting from Technology. Harvard Business Press, 2003.

[2] P. Geroski, S. Machin, and J. van Reenen, "The profitability of innovating firms," RAND Journal of Economics, vol. 14, pp. 198-211, 1993.

[3] D. B. Audretsch, "Innovation, Growth and Survival," International Journal of Industrial Organization, vol. 13, no. 4, pp. 441-457, 1995.

[4] J. F. Bard, R. Balachandra and P. E. Kaufmann, "An Interactive Approach to R\&D Project Selection and Termination," IEEE Transactions on Engineering Management, vol. 35, no. 3, pp. 139-146, 1988.

[5] R. Balachandra, K. K. Brockhoff and A. W. Pearson "R\&D project termination decisions: Processes, communication, and personnel changes," Journal of Product Innovation Management, vol. 13, no. 3, pp. 245-256, 1996.

[6] J. A. Raelin and R. Balachandra, "R\&D Project Termination in High-Tech Industries," IEEE Transactions on Engineering Management, vol. EM-32, no. 1, pp. 16-23, 1985.

[7] M. Asplund, M. and R. Sandin, "The Survival of New Products," Review of Industrial Organization, vol. 15, no. 3, 219-237, 1999.

[8] A. J. Cozijnsen, W. J. Vrakking, and M. van Ijzerloo, "Success and failure of 50 innovation projects in Dutch companies," European Journal of Innovation Management, vol. 3, pp. 150-159, 2000.

[9] F. Galia and D. Legros, "Complementarities between obstacles to innovation: evidence from France,“ Research Policy, vol. 33, no. 8, pp. 1185-1199, 2004.

[10] P. D'Este, S Iammarino, M Savona, and N von Tunzelmann, "What hampers innovation? Revealed barriers versus deterring barriers," Research Policy, vol. 41, no. 2, pp. 482-488, 2012.

[11] P. Blanchard, J.-P. Huiban, A. Musolesi and P. Sevestre, "Where there is a will, there is a way? Assessing the impact of obstacles to innovation," Industrial and Corporate Change, vol. 22, no. 3, pp. 679-710, 2013.

[12] R. Leoncini, "Learning-by-failing. An empirical exercise on CIS data," Research Policy, vol. 45, pp. 376-386, 2016.

[13] V. Kumar, A. N. S. Persaud and U. Kumar, "To Terminate or Not an Ongoing R\&D Project: A Managerial Dilemma," IEEE Transactions on Engineering Management, vol. 43, no. 3, pp. 273-284, 1996.

[14] G. van der Panne, C. van Beers, and A. Kleinknecht, "Success and Failure of Innovation: A Literature Review," International Journal of Innovation Management, vol. 7, no. 3, 309-338, 2003.

[15] J.-Y.Kim and A. S. Miner, "Vicarious Learning from the Failures and Near-Failures of Others: Evidence from the U.S. Commercial Banking Industry," Academy of Management Journal, vol. 50, no. 3, pp. 687-714, 2007.

[16] J. K. Pinto and S. J. Mantel, Jr., "The Causes of Project Failure," IEEE Transactions on Engineering Management, vol. 37, no. 4, pp. 269-276, 1990.

[17] R. W. Peck, D. W. Lendrem, I. Grant, B. C. Lendrem and J. D. Isaacs, "Why is it hard to terminate failing projects in pharmaceutical R\&D?," Nature Reviews Drug Discovery, vol. 14, no. 10, pp. 663-664, 2015.

[18] C. Wallin and J. J. Gilman, "Determining the optimum level for R\&D spending," Research Management, vol. 29, no. 5, pp. 19-24, 1986. 
[19] R. Balachandra, "A Comparison of R\&D Project Termination Factors in Four Industrial Nations", IEEE Transactions on Engineering Management, vol. 43, no. 1, pp. 88-96, 1996.

[20] S. Lhuillery, and E. Pfister, "R\&D cooperation and failures in innovation projects: Empirical evidence from French CIS data," Research Policy, vol. 38, pp. 45-57, 2009.

[21] C. Freeman, A. B. Robertson, B. G. Achilladelis, and P. Jervis, "Success and failure in industrial innovation," Report on Project SAPPHO by the Science Policy Research Unit. London: Center for the Study of Industrial Innovation, University of Sussex, 1972.

[22] R. G. Cooper, "Project NewProd: factors in new product success," European Journal of Marketing, vol. 14, pp. 277-292, 1980.

[23] M. A. Maidique and B. J. Zirger, "A study of success and failure in product innovation: The case of the U.S. electronics industry," IEEE Transactions on Engineering Management, vol. 31, no. 4, pp. 192-203, 1984.

[24] J. K., Pinto and D. P. Slevin, "Critical success factors in project management," IEEE Transactions on Engineering Management, vol. 34, no. (1), pp. 22-27, February 1987.

[25] R. J. Calantone, C. A. Benedetto, and R. Divine, "Organizational, technical and marketing antecedents for successful new product development," R\&D Management, vol. 23, pp. 337-349, 1993.

[26] D. H. Lester, "Critical success factors for new product development. Research Technology Management, vol. 41, no. 1, pp. 36-43, 1998.

[27] R. Stuart and P. A. Abetti, "Start-up ventures: Towards the prediction of initial success," Journal of Business Venturing, vol. 2, pp. 215-230, 1987.

[29] J. Bessant and J. Buckingham, "Innovation and Organizational Learning: the Case of Computer-Aided Production Management," British Journal of Management, vol. 4, no. 4, pp. 219-234, 1993.

[29] Y. Wind and V. Mahajan, "New Product Development Process: A Perspective for Reexamination," Journal of Product Innovation Management, vol. 5, no. 4, pp. 304-310, 1988.

[30] W. M. Cohen and D. A. Levinthal, "Absorptive Capacity: A New Perspective on Learning and Innovation," Administrative Science Quarterly, vol. 35, no. 1, pp. 128-152, 1990.

[31] R. Rothwell, "Successful industrial innovation: Critical success factors for the 1990s," $R \& D$ Management, vol. 3, pp. 221-239, 1992.

[32] A. L. Page, "Assessing new product development practices and performance: Establishing crucial norms," Journal of Product Innovation Management, vol. 10, pp. 273- 287, 1993.

[33] J. B. Roure and R. H. Keeley, "Predictors of success in new technology based ventures," Journal of Business Venturing, vol. 5, pp. 221-239, 1990.

[34] R. G. Cooper, "The impact of new product strategies," Industrial Marketing Management, vol. 12, pp. 243-256, 1983.

[35] Cottam, A., Ensor, J., Band, C., 2001. A benchmark study of strategic commitment to innovation. European Journal of Innovation Management, vol. 4, pp. 88-94, 2001.

[36] D. H. Gobeli and D. J. Brown, "Analyzing product innovations," Research Management, vol. 30, no. 4, pp. 25-30, 1987.

[37] R. G. Cooper, Winning at New Products: Accelerating the Process from Idea to Launch. Reading, MA: Addison-Wesley, 1993.

[38] B. J. Zirger and M. A. Maidique, “A Model of New Product Development: An Empirical Test," Management Science, vol. 36, no. 7, pp. 867-883, 1990.

[39] R. G. Cooper and E. J. Kleinschmidt, "New Products: What Separates Winners from Losers?," Journal of Product Innovation Management, vol. 4, no. 3, pp. 169-184, 1987. 
[40] R. G. Cooper and E. J. Kleinschmidt, "Benchmarking the Firm's Critical Success Factors in New Product Development," Journal of Product Innovation Management, vol. 12, no. (5), pp. 374-391, 1995.

[41] P. Link, "Keys to new product success and failure," Journal of Industrial Marketing Management, vol. 16, pp. 109-118, 1987.

[42] D. S. Hopkins, "New-product winners and losers," Research Management, vol. 24, no. 3, pp. 12-17, 1981.

[43] A. Canepa and P. Stoneman, "Financing constraints in the inter firm diffusion of new process technologies," Journal of Technology Transfer, vol. 30, no. 2, pp. 159-169, 2005.

[44] P. Mohnen, P. and L-H. Roller, "Complementarities in innovation policy," European Economic Review, vol. 49, pp. 1431-1450, 2005.

[45] P. Mohnen, F. C. Palm, S. S. van der Loeff, and A. K. Tiwari, "Financial constraints and other obstacles: Are they a threat to innovation activity?," De Economist, vol. 156, no. 2, pp. 201$214,2008$.

[46] M. Garcia-Vega and A. Lopez, "Determinants of abandoning innovative activities: evidence from Spanish Firms," Cuadernos de Economía y Dirección de la Empresa, vol. 13, no. 45, pp. 69-91, 2010.

[47] F. Savignac, "Impact of Financial Constraints on Innovation: What Can Be Learned From a Direct Measure?," Economics of Innovation and New Technology, vol. 17, no. 6, pp. 553-569, 2008.

[48] A. Y. Lewin, S. Massini and C. Peeters, "Microfoundations of internal and external absorptive capacity routines," Organization Science, vol. 22, no. 1, pp. 81-98, 2011.

[49] M. S. Salerno, L. A. Gomes, D. Oliveira da Silva, R. B. Bagno, and S. L. Freitas, , "Innovation processes: Which process for which project?," Technovation, vol. 35, pp. 59-70, 2015.

[50] R. Rothwell and A. B. Robertson, "The role of communications in technological innovation," Research Policy, vol. 2, no. 3, pp. 204-225, 1973.

[51] R. G. Cooper, "Perspective: The Stage-Gate ${ }^{\circledR}$ Idea-to-Launch Process-Update, What's New, and NexGen Systems"," Journal of Product Innovation Management, vol. 25, no. 3, pp. 213-232, 2008.

[52] R. Manzini and V. Lazzarotti, "Intellectual property protection mechanisms in collaborative new product development,“ $R \& D$ Management, vol. 46, no. 52, pp. 579-595, 2015.

[53] R. G. Cooper, "A Process Model for Industrial New Product Development," IEEE Transactions on Engineering Management, vol. 30, no. 1, pp. 2-11, 1983.

[54] K. K. Brockhoff, "R\&D project termination decisions by discriminant analysis-An international comparison," IEEE Transactions on Engineering Management, vol. 41, no. 3, pp. 245-254, 1994.

[55] S. K. Tadisina, "Support systems for the termination decision in R\&D management," Project Management Journal, vol. 17, pp. 97-104, 1986.

[56] A. H. Rubenstein, A. K. Chakrabarti, R. D. O'Keefe, W. E. Sonder and H. C. Young, "Factors Influencing Success at the Project Level," Research Management, Vol. XIX, no. 3, pp. 15-20, 1976.

[57] R. T. Holzmann, "To stop or not: The big research decision," IEEE Engineering Management Review, vol. 2, pp. 56-64, 1974.

[58] D. Teece, G. Pisano, and A. Shuen, "Dynamic Capabilities and Strategic Management," Strategic Management Journal, vol. 18, no. 7, pp. 509-533, 1997.

[59] S. G. Winter, "Understanding dynamic capabilities," Strategic Management Journal, vol. 24, no. 10, pp. 991-995, 2003. 
[60] K. M. Eisenhardt and J. A. Martin, "Dynamic capabilities: what are they?," Strategic Management Journal, vol. 21, no. 10-11, pp. 1105-1121, 2000.

[61] R. Katila and S. Shane, "When does lack of resources make new firms innovative?," Academy of Management Journal, vol. 48, no. 5, pp. 814-829, 2005.

[62] M.T. Hannan and J. Freeman, "Structural inertia and organizational change," American Sociological Review, vol. 49, no. 2, pp. 149-164, 1984.

[63] J. R. Allison, M. A. Lemley, K. A. Moore, and R. D. Trunkey, "Valuable patents," Georgetown Law Journal, vol. 92, no. 3, pp. 435-479, 2004.

[64] D. Harhoff, F. M. Scherer, and K. Vopel, "Citations, family size, opposition and the value of patent rights," Research Policy, vol. 32, pp. 1343-1363, 2003.

[65] K. Hussinger, "Is Silence Golden? Patents versus Secrecy at the Firm Level," Economics of Innovation and New Technology, vol. 15, no. 8, pp. 735-752, 2006.

[66] J. Hagedorn and N. Wang, "Is there complementarity or substitutability between internal and external R\&D strategies?," Research Policy, vol. 41, pp. 1072-1083, 2012.

[67] M. A. Hitt, R. E. Hoskisson, R. Duane Ireland, "Mergers and acquisitions and managerial commitment to innovation in M-form firms," Strategic Management Journal, vol. 11, pp. 29-47, 1990.

[68] Z. Griliches, "Patent statistics as economic indicators: a survey," Journal of Economic Literature, vol. 28, pp. 1661-1707, 1990.

[69] J. Hausman, B. H. Hall and Z. Griliches, "Econometric models for count data with an application to the patents-R\&D relationship," Econometrica, vol. 52, pp. 909-938, 1984.

[70] B. Wernerfelt and A. Karnani, "Competitive strategy under uncertainty," Strategic Management Journal, vol. 8, pp. 187-194, 1987.

[71] A. Leiponen and J. Byma, "If you cannot block, you better run: Small firms, cooperative innovation, and appropriation strategies," Research Policy, vol. 38, no. 9, pp. 1478-1488, 2009.

[72] B. Cassiman and R. Veugelers, "In Search of Complementarity in Innovation Strategy: Internal R\&D and External Knowledge Acquisition," Management Science, vol. 52, no. 1, pp. 68-82, 2006.

[73] B. Lokshin, R. Belderbos, and M. Carrée, "The Productivity Effects of Internal and External R\&D: Evidence from a Dynamic Panel Data Model," Oxford Bulletin of Economics and Statistics, vol. 70, no. 3, pp. 399-413, 2008.

[74] F. T. Rothaermel and A. M. Hess, "Building dynamic capabilities: Innovation driven by individual-, firm-, and network-level effects," Organization Science, vol. 18, pp. 898-921, 2007.

[75] R. Veugelers, "Internal R \& D expenditures and external technology sourcing," Research Policy, vol. 26, pp. 303-315, 1997.

[76] H. W. Chesbrough, Open Business Models: How to Thrive in the New Innovation Landscape, Harvard Business School Press, 2006.

[77] D. B. Audretsch, A. J. Menkveld and A. R. Thurik, "The decision between internal and external R\&D,” Journal of Institutional and Theoretical Economics, vol. 152, pp. 519-530, 1996.

[78] P. Beneito, "The innovative performance of in-house and contracted R\&D in terms of patents and utility models," Research Policy, vol. 35, pp. 502-517, 2006.

[79] E. Brouwer, H. Budil-Nadvornikova, and A. Kleinknecht, "Are urban agglomerations a better breeding place for product innovation? An analysis of new product announcements," Regional Studies, vol. 33, no. 6, pp. 541-549, 1999.

[80] B. M. Staw and J. Ross, "Knowing when to pull the plug," Harvard Business Review, vol. 65, no. 2, pp. 68-74, 1987.

[81] A. Lam, "Organizational Innovation," In: J. Fagerberg, D. C. Mowery, and R. R. Nelson (Eds.) The Oxford Handbook of Innovation. Oxford University Press, 2005. 
[82] S. W. Floyd and P. J. Lane, "Strategizing throughout the organization: Managing role conflict in strategic renewal," Academy of Management Review, vol. 25, no. 1, pp. 154-177, 2000.

[83] H. Armbruster, A. Bikfalvi, S. Kinkel, and G. Lay, "Organizational innovation: The challenge of measuring non-technical innovation in large-scale surveys," Technovation, vol. 28, no. 10, pp. 644-657, 2008.

[84] M. A. Hitt, R. E. Hoskisson, and H. Kim, "International diversification: effects on innovation and firm performance in product-diversified firms," Academy of Management Journal, vol. 40, no. 4, pp. 767-798, 1997.

[85] J. W. Lu and P. W., Beamish, "International diversification and firm performance: the Scurve hypothesis," Academy of Management Journal, vol. 47, no. 4, pp. 598-609, 2004.

[86] B. Kogut and U. Zander, "Knowledge of the firm and the evolutionary theory of the multinational corporation," Journal of International Business Studies, vol. 24, no. 4, pp. 625-645, 1993.

[87] M. Kotabe, "Corporate product policy and innovative behavior of European and Japanese multinationals: an empirical investigation," Journal of Marketing, vol. 54, pp. 19-33, 1990.

[88] S. J. Kobrin, "An empirical analysis of the determinants of global integration," Strategic Management Journal, vol. 12, no. (S1), pp. 17-31, 1991.

[89] A. Delios and W. J. Henisz, "Political hazards, experience, and sequential entry strategies: the international expansion of Japanese firms, 1980-1998," Strategic Management Journal, vol. 24, no. 11, pp. 1153-1164, 2003.

[90] R. M. Grant, "Multinationality and performance among British manufacturing companies," Journal of International Business Studies, vol. 18, no. 3, pp. 79-89, 1987.

[91] S. Hymer, The international operations of nation firms: a study of foreign direct investment. Cambridge: MLT Press.

[92] J. A. Schumpeter, Capitalism, socialism, and democracy. 3rd ed. New York: Harper and Row, 1950.

[93] Z. J. Acs and D. B. Audretsch, "Innovation, Market Structure, and Firm Size," Review of Economics and Statistics, vol. 69, no. 4, pp. 567-574, 1987.

[94] F. M. Scherer, "Firm Size, Market Structure, Opportunity, and the Output of Patented Inventions," American Economic Review, vol. 55, pp. 1097-1125, 1965.

[95] A. K. Kohli and B. J. Jaworski, "Market Orientation: The Construct, Research Propositions, and Managerial Implications,” Journal of Marketing, vol. 54, pp. 1-18, 1991.

[96] S. F. Slater and J. C. Narver, "The Positive Effect of a Market Orientation on Business Profitability: A Balanced Replication," Journal of Business Research, vol. 48, no. 1, pp. 69-73, 2000.

[97] A. M. Pelham, "Market orientation and other potential influences on performance in small \& medium sized manufacturing firms," Journal of Small Business Management, vol. 38, pp. 48-67, 2000.

[98] F. J .H. M. Verhees and M. T. G. Meulenberg, "Market Orientation, Innovativeness, Product Innovation, and Performance in Small Firms," Journal of Small Business Management, vol. 42, no. 2, pp. 134-154, 2004.

[99] K. Atuahene-Gima, "Market orientation and innovation," Journal of Business Research, vol. 35, no. 2, pp. 93-103, 1996.

[100] D. W. Vorhies, R. E. Morgan, and C. W. Autry, "Product-market strategy and the marketing capabilities of the firm: Impact on market effectiveness and cash flow performance," Strategic Management Journal, vol. 30, no. 12, pp. 1310-1334, 2009. 
[101] OECD, "Proposed Guidelines for Collecting and Interpreting Technology Innovation Data - Oslo Manual," OECD: Paris, 1992.

[102] OECD, "Proposed Guidelines for Collecting and Interpreting Technology Innovation Data - Oslo Manual," $2^{\text {nd }}$ ed. OECD: Paris, 1996.

[103] OECD, "Proposed Guidelines for Collecting and Interpreting Technology Innovation Data - Oslo Manual," $3{ }^{\text {rd }}$ ed. OECD: Paris, 2005.

[104] J. Mairesse and P. Mohnen, "Using innovation surveys for econometric analysis," In: B. H. Hall and N. Rosenberg, N. (Eds.) Handbook of the economics of innovation. Amsterdam: Elsevier, pp. 1130-1155, 2010.

[105] R. Evangelista, S. Iammarino, V. Mastrostefano, and A. Silvani, "Measuring the regional dimension of innovation. Lessons from the Italian Innovation Survey," Technovation, vol. 21, no. 11, pp. 733-745, 2001.

[106] R. Harrison, J. Jaumandreu, J. Mairesse, and B. Peters, "Does innovation stimulate employment? A firm-level analysis using comparable micro-data from four European countries," International Journal of Industrial Organization, vol. 35, pp. 29-43, 2014.

[107] D. Czarnitzki and C. Lopes Bento, "Evaluation of public R\&D policies: A cross-country comparison," World Review of Science, Technology and Sustainable Development, vol. 9, no. 2/3/4, pp. 254-282, 2012.

[108] J. Horbach, V. Oltra, and J. Belin, "Determinants and Specificities of Eco-Innovations Compared to Other Innovations: An Econometric Analysis for the French and German Industry Based on the Community Innovation Survey," Industry and Innovation, vol. 20, no. 6, pp. 523543, 2013.

[109] I. M. B. Freitas, T. H. Clausen, R. Fontana, and B. Verspagen, "Formal and informal external linkages and firms' innovative strategies. A cross-country comparison," Journal of Evolutionary Economics, vol. 21, no. 1, pp. 91-119, 2011.

[110] P. Therrien and P. Mohnen, "How Innovative Are Canadian Firms Compared to Some European Firms?: A Comparative Look at Innovation Surveys," Technovation, vol. 23, no. 4, pp. 359-69.

[111] Eurostat, "High-tech industry and knowledge-intensive services. Reference Metadata in Euro SDMX Metadata Structure. Annex 3 - High-tech aggregation by NACE Rev. 2," Available at http://ec.europa.eu/eurostat/cache/metadata/en/htec_esms.htm\#annex1455195414029, 2016.

[112] M. J. Benner and M. Tushman, "Process management and technological innovation: A longitudinal study of the photography and paint industries," Administrative Science Quarterly, vol. 47, no.,4 pp. 676-707, 2002.

[113] J. K. Christiansen and C. J. Varnes, "Formal rules in product development: Sensemaking of structured approaches," Journal of Product Innovation Management, vol. 26, no. 5, pp. 502519, 2009.

[114] C. Schultz, S. Salomo, U. De Brentani, and E. J. Kleinschmidt, "How formal control influences decision-making clarity and innovation performance," Journal of Product Innovation Management, vol. 30, no. 3, pp. 430-447, 2013.

[115] S. L. Brown and K. M. Eisenhardt, "Product development: Past research, present findings, and future directions," Academy of Management Review, vol. 20, no. 2, pp. 343-378, 1995.

[116] M. V. Tatikonda and M. M. Montoya-Weiss, "Integrating operations and marketing perspectives of product innovation: The influence of organizational process factors and capabilities on development performance," Management Science, vol. 47, no. 1, pp. 151 - 172.

[117] M. A. Saren, "A classification and review of models of the intra-firm innovation process," R\&D Management, vol. 14, no. 1, pp. 11-24, 1984. 
[118] R. Rothwell, "Towards the Fifth-generation Innovation Process," International Marketing Review, vol. 11, no. 1, pp. 7-31, 1994.

[119] W. Ocasio, "Towards an attention-based view of the firm," Strategic Management Journal, vol. 18, no. S1, pp. 187-206, 1997.

[120] L. Argote, S. L. Beckman, and D. Epple, "The Persistence and Transfer of Learning in Industrial Settings," Management Science, vol. 36, no. 2, pp. 140-154, 1990.

[121] V. Chiesa and F. Frattini, "Commercializing Technological Innovation: Learning from Failures in High-Tech Markets," Journal of Product Innovation Management, vol. 28, no. 4, pp. 437-454, 2011.

[122] J. Lampel, J. Shamsie, and Z, Shapira, "Experiencing the Improbable: Rare Events and Organizational Learning,” Organization Science, vol. 20, no. 5, pp. 835-845, 2009.

\section{References in Footnotes}

M. A. Saren, "A classification and review of models of the intra-firm innovation process," $R \& D$ Management, vol. 14, no. 1, pp. 11-24, 1984.

M. L. Tushman, "Special Boundary Roles in the Innovation Process," Administrative Science Quarterly, vol. 22, no. 4, pp. 587-605, 1977.

J. M. Utterback, "The Process of Technological Innovation Within the Firm," Academy of Management Journal, vol. 14, no. 1, pp. 75-88, 1971.

J. M. Utterback, "Innovation in industry and the diffusion of technology," Science, vol. 183, no. 4125, pp. 620-626, 1974. 